\title{
Prenatal Drug Exposure Affects Neonatal Brain Functional Connectivity
}

\author{
Andrew P. Salzwedel, ${ }^{1}$ @Karen M. Grewen, ${ }^{2}$ CClement Vachet, ${ }^{3}$ Guido Gerig, ${ }^{3}$ Weili Lin, ${ }^{1}$ and $\odot$ Wei Gao ${ }^{1}$ \\ ${ }^{1}$ Department of Radiology and Biomedical Research Imaging Center and ${ }^{2}$ Department of Psychiatry, Neurobiology, and Psychology, University of North \\ Carolina at Chapel Hill, Chapel Hill, North Carolina 27599, and ${ }^{3}$ Scientific Computing and Imaging Institute, University of Utah, Salt Lake City, Utah 84112
}

Prenatal drug exposure, particularly prenatal cocaine exposure (PCE), incurs great public and scientific interest because of its associated neurodevelopmental consequences. However, the neural underpinnings of PCE remain essentially uncharted, and existing studies in school-aged children and adolescents are confounded greatly by postnatal environmental factors. In this study, leveraging a large neonate sample $(N=152)$ and non-invasive resting-state functional magnetic resonance imaging, we compared human infants with PCE comorbid with other drugs (such as nicotine, alcohol, marijuana, and antidepressant) with infants with similar non-cocaine poly drug exposure and drug-free controls. We aimed to characterize the neural correlates of PCE based on functional connectivity measurements of the amygdala and insula at the earliest stage of development. Our results revealed common drug exposure-related connectivity disruptions within the amygdala-frontal, insula-frontal, and insula-sensorimotor circuits. Moreover, a cocaine-specific effect was detected within a subregion of the amygdala-frontal network. This pathway is thought to play an important role in arousal regulation, which has been shown to be irregular in PCE infants and adolescents. These novel results provide the earliest human-based functional delineations of the neural-developmental consequences of prenatal drug exposure and thus open a new window for the advancement of effective strategies aimed at early risk identification and intervention.

Key words: amygdala; fMRI; functional connectivity; infant; insula; prenatal drug exposure

\section{Introduction}

Prenatal drug exposure is a significant public health concern. Particularly, prenatal cocaine exposure (PCE) has attracted considerable attention given its well documented influence on developmental and behavioral outcomes (Lambert and Bauer, 2012). However, the neural correlates of PCE in humans have been scarcely studied, and the results are inconsistent. The few existing studies are limited to late childhood (Smith et al., 2001; DowEdwards et al., 2006) and adolescence (Rao et al., 2007; Hurt et al., 2008; Sheinkopf et al., 2009; Li et al., 2011, 2013), which, although informative, are likely confounded by adverse postnatal environmental circumstances that often accompany maternal drug use (Yumoto et al., 2008; Eiden et al., 2014). However, deficits in attention and arousal regulation have been observed readily in neonates with PCE (Bard et al., 2000; Lester et al., 2002; Eiden et al., 2009), suggesting the earliest existence of drug-related devel-

Received 0ct. 20, 2014; revised Feb. 24, 2015; accepted March 1, 2015.

Author contributions: A.P.S., K.M.G., and W.G. designed research; A.P.S., K.M.G., and W.G. performed research; A.P.S., K.M.G., and W.G. analyzed data; A.P.S., K.M.G., C.V., G.G., W.L., and W.G. wrote the paper.

This study was supported by National Institutes of Health Grant R03 DA036645-01A1 (W.G. and K.M.G.) and P01DA022446 (K.M.G.) and University of North Carolina at Chapel Hill startup funds (W.G.).

The authors declare no competing financial interests.

Correspondence should be addressed to either of the following: Dr. Wei Gao, University of North Carolina at Chapel Hill, Department of Radiology and Biomedical Research Imaging Center, Room 3105, Bioinformatics Building, Chapel Hill, NC 27599, E-mail: wgao@email.unc.edu; or Dr. Karen M. Grewen, University of North Carolina at Chapel Hill, Department of Psychiatry, 256 Medical Wing D, Emergency Room Drive, Campus Box 7175, Chapel Hill, NC 27599-7175. E-mail: Karen_Grewen@med.unc.edu.

DOI:10.1523/JNEUROSCI.4333-14.2015

Copyright $\odot 2015$ the authors $\quad 0270-6474 / 15 / 355860-10 \$ 15.00 / 0$ opmental effects. Therefore, it is imperative to delineate the neural underpinnings of PCE during the earliest stages of brain development.

Previous neuroimaging studies of PCE in infants are mostly limited to structural explorations (Grewen et al., 2014). However, the brain undergoes dramatic functional development prenatally (Doria et al., 2010; Thomason et al., 2013; Gao et al., 2014a,b), so it is likely that PCE has already left a footprint on the functional organization of the brain before birth. Indeed, neonatal electroencephalography (EEG) studies show delayed brain functional maturation and reduced interhemispheric functional connectivity in 1-month-old infants with PCE (Scher et al., 2000; Lester et al., 2003). Compared with EEG, recent advances in the restingstate functional magnetic resonance imaging (rsfMRI) technique offer an improved opportunity to non-invasively probe the functional organization of the whole brain during infancy (Gao et al., 2009, 2011, 2013, 2014a, 2015; Smyser et al., 2010; Fransson et al., 2011). Therefore, rsfMRI-based explorations in neonates would likely further advance our understanding of the neural correlates of PCE and potentially facilitate future intervention efforts.

In this study, three groups of neonates underwent rsfMRI scans: (1) 45 PCE infants with or without in utero exposure to marijuana, alcohol, nicotine, antidepressant [serotonin-specific reuptake inhibitor (SSRI) ], and others; (2) 43 with in utero exposure to some combination of non-cocaine drugs (NCOC); and (3) 64 drug-free controls (CTR). Functional connectivity analyses were done based on two regions of interest, the amygdala and the insula. These two regions were selected because of the follow- 
ing: (1) they experience the earliest prenatal structural and functional growth (Ulfig et al., 2003; Afif et al., 2007); and (2) disruptions of their functional connectivity have been reported in both cocaine-dependent adults (Gu et al., 2010; Cisler et al., 2013; McHugh et al., 2013) and adolescents with PCE (Li et al., 2011, 2013). Given the observed arousal dysregulation in neonates with PCE, we hypothesized that PCE-related alterations in brain connectivity would also be present, particularly between the areas of the amygdala/insula and prefrontal cortex (PFC; Cisler et al., 2013; Li et al., 2013). Moreover, we predicted cocaine-specific alterations in connectivity compared with other drugs.

\section{Materials and Methods}

Participants. Infants were part of an ongoing study of the neurodevelopmental effects of PCE. Results reported here include 152 infants. Inclusion/exclusion criteria have been described previously (Grewen et al., 2014). One hundred nineteen infants (33 for PCE, 40 for NCOC, and 46 for CTL) completing the neonatal MRI scan with good data were included in the study by Grewen et al., whereas the current study used a larger sample that included an additional 33 infants ( 12 for PCE, 3 for NCOC, and 18 for CTL). Pregnant women were recruited in the third trimester of pregnancy. Primary recruitment sites for PCE and NCOC participants were local residential and outpatient treatment programs for women with perinatal substance abuse and their children. Specifically, we recruited both CTR and drug-exposed mothers from Chatham, Orange, Durham, Alamance, and Wake County Health Department obstetric clinics, the University of North Carolina hospital low-income obstetrics clinic, and flyers, local advertisements, and Craigslist. All participants were tested for perinatal drug use using interviews, medical record review, and postnatal urine toxicology at study visits. Drug-use status was based on three criteria: (1) self-report on a time-line followback interview conducted at 1 month postpartum; (2) response to a questionnaire about maternal substance use done at 3 months; and (3) medical record queries of prenatal urine toxicology. Maternal self-report or positive urine toxicology for cocaine qualified the mother-infant dyad for PCE status. The study sample ( $N=152,77$ males and 75 females) consisted of the following: (1) 45 infants from the PCE group; (2) 43 infants from the NCOC group; and (3) 64 infants from the CTR group. Participants were further characterized according to gestational age at birth, postnatal age (gestational age at scan), and birth weight. Birth weight data were unavailable for two participants. Prenatal and postnatal categorical drug use was characterized in the drug-using groups. Postnatal drug exposure information (i.e., postnatal maternal drug use plus feeding mode) was available for a subset of the cohort. Approximately half $(n=77)$ of the mothers breastfed exclusively or in combination with formula. Postnatal maternal drug use was minimal for cocaine $(n=2)$, marijuana $(n=4)$, alcohol $(n=7)$, and other $(n=10)$ and was moderate for nicotine $(n=38)$. The numbers of neonates exposed to the combination of postnatal maternal drug use and breastfeeding (i.e., with effective postnatal drug exposure) were $n=0$ for cocaine, $n=0$ for marijuana, $n=2$ for alcohol ( 1 for CTR and 1 for NCOC), $n=3$ for other ( 1 for PCE and 2 for NCOC), and $n=17$ for nicotine ( 9 for PCE and 8 for NCOC). Therefore, postnatal drug exposure is present in a small subset and thus likely has minimal effects on the functional connectivity analysis. Note, however, that postnatal nicotine exposure from second-hand smoke inhalation represents an alternative pathway for effective postnatal exposure. Nevertheless, because of the inherent difficulty in the evaluation and quantification of this channel of exposure, its effects are hard to characterize and are beyond the scope of this study. We obtained information on family income and maternal education, as well as maternal depression levels. However, income is unlikely to be a faithful representation of socioeconomic status (SES) because of the fact that a large number of drug-using women in the sample were living in residential treatment for varying lengths of time during pregnancy and postpartum. Therefore, even if family income was zero, mother-infant dyads still had a safe, violence-free place to live and all basic needs met, unlike women living in the community. Thus, maternal education $(n=123)$ and depression level $(n=147)$ were used as potential explanatory variables to test the effects of environmental factors (SES and caregiver traits). Specifically, maternal education was determined by self-report and ranged from some high school to postgraduate work in this sample. Rank scores were as follows: 3 , some high school; 4 , graduated from high school; 5 , trade school or business college; 6 , some college; 7 , graduated with a 4 year college degree; and 8 , postgraduate work at a university. Maternal depression level was determined by scores on the Edinburgh Postnatal Depression Scale and was measured at the time of the infant MRI (2-4 weeks postpartum). Participant (mother and infant) characteristics were compared statistically: group means were compared using the ANOVA method, and group proportions were tested using the $\chi^{2}$ statistic $\left(\chi^{2}\right.$ with Yates' correction for continuity). This study was approved by the Biomedical Institutional Review Board of the University of North Carolina at Chapel Hill.

Imaging and preprocessing. Before imaging, each participant was fed, swaddled, and fitted with ear protection. Subjects were not sedated but slept during image acquisition. Head position was secured in the scanner using a vacuum-fixation device. Vital signs (heart rate, $\mathrm{SaO}_{2}$ ) were monitored continuously by a nurse throughout the examination. Data were collected using two scanners: (1) 3T head-only Siemens Allegra with circular polarization head coil ( $n=89 ; 14$ for PCE, 34 for NCOC, and 41 for CTR); and (2) 3T Siemens Tim Trio with 32-channel head coil ( $n=$ 63; 31 for PCE, 9 for NCOC, and 23 for CTR. T1-weighted structural images were collected using a 3D magnetization-prepared rapid acquisition gradient echo pulse sequences: repetition time (TR), $1820 \mathrm{~ms}$; echo time (TE), $3.75 \mathrm{~ms}$; inversion time, $1100 \mathrm{~ms}$; flip angle, $7^{\circ}$; 144 slices; voxel size, $1 \mathrm{~mm}^{3}$. A small number of subjects $(n=5)$ were excluded as a result of severe motion during the anatomical acquisition. rsfMRIs were acquired using a $\mathrm{T} 2{ }^{*}$-weighted echo planar imaging pulse sequence: TR, 2 s; TE, $32 \mathrm{~ms}$; 33 slices; voxel size, $4 \mathrm{~mm}^{3}$; number of volumes, 150 ( $5 \mathrm{~min})$. Subjects were excluded $(n=8)$ if the final number of volumes was $<90$ after data preprocessing (see below, Functional connectivity analyses).

Functional data were preprocessed using a common pipeline in the FMRIB (for Functional MRI of the Brain) Software Library (FSL; version 4.1.9) (Jenkinson et al., 2012). Steps included discarding the first 10 volumes $(20 \mathrm{~s})$, slice-timing correction, rigid-body motion correction, spatial smoothing (Gaussian kernel FWHM of $6 \mathrm{~mm}$ ), bandpass filtering $(0.01-0.08 \mathrm{~Hz})$, and regression of whole brain [global signal regression (GSR)], white matter, CSF, and the six motion parameters. Data scrubbing was also implemented; scrubbing criteria, $0.5 \%$ signal change and $0.5 \mathrm{~mm}$ framewise displacement (Power et al., 2012). Scrubbing parameters (volumes removed and residual framewise displacement) were compared at the group level using the ANOVA method. FSL and the Analysis of Functional NeuroImages software suite (AFNI version 2011-12-21-1014; Cox, 1996) were used to process the structural images. Structural image skull stripping was done using a two-step process. First, FSL-bet2 (options: $-\mathrm{f} 0.3-\mathrm{g}-1.0$ ) was used to perform an initial skull strip, and then the result was bolstered using the AFNI script@NoisySkullStrip (options:-use_skull-blur_fwhm 1-init_radius 25). Alignment of functional data into a common space involved two steps: (1) within-subject rigid alignment [FSL FLIRT (for FMRIB Linear Image Restoration Tool)] between functional and T1-weighted images; and (2) nonlinear [FSL FNIRT (for FMRIB Nonlinear Image Registration Tool)] registration of the T1-weighted images to a T1weighted template image acquired from an independent subject scanned at 2 weeks of age. The combined transformation field (linear plus nonlinear) was used to warp the preprocessed rsfMRI data to the template space. Alignment was inspected visually for quality across all subjects. Amygdala and insula regions were defined using the Harvard-Oxford probabilistic atlas (Desikan et al., 2006) provided with FSL. The atlas was warped into the study-specific template space using 4D HAMMER (Shen and Davatzikos, 2004).

Functional connectivity analyses. Standard seed-based whole-brain functional connectivity analyses were performed using the temporal correlation method (Biswal et al., 1995). Briefly, for each seed region, the average BOLD time series was computed and then cross-correlated with the time series of every voxel in the brain. This resulted in a seed-specific correlation value — signifying functional connectivity—for each subject 
Table 1. Summary of participant characteristics

\begin{tabular}{|c|c|c|c|c|c|c|c|c|c|}
\hline & PCE & $\mathrm{NCOC}$ & CTR & For $\chi^{2}$ & $p$ & $\eta_{p}^{2}$ & PCE versus NCOC & PCE versus CTR & NCOC versus CTR \\
\hline \multicolumn{10}{|l|}{ Infant } \\
\hline$n$ (females) & $45(24)$ & $43(24)$ & $64(27)$ & 1.67 & 0.433 & & & & \\
\hline Gestational age (d) & $272 \pm 1.65$ & $280 \pm 1.20$ & $278 \pm 1.03$ & 8.10 & $<0.001$ & 0.10 & 0.001 & 0.003 & 0.871 \\
\hline Postnatal age (d) & $308 \pm 2.92$ & $305 \pm 1.53$ & $306 \pm 1.41$ & 0.80 & 0.453 & 0.01 & & & \\
\hline Birth weight (pounds) & $6.70 \pm 0.15$ & $7.51 \pm 0.17$ & $7.59 \pm 0.12$ & 11.03 & $<0.001$ & 0.13 & $<0.001$ & $<0.001$ & 0.971 \\
\hline \multicolumn{10}{|l|}{ Mother } \\
\hline Education (rank score) $^{a}$ & $4.82 \pm 0.22$ & $5.18 \pm 0.27$ & $6.20 \pm 0.22$ & 9.59 & $<0.001$ & 0.14 & 0.719 & $<0.001$ & 0.010 \\
\hline Depression (scale) & $5.89 \pm 0.72$ & $5.32 \pm 0.96$ & $3.32 \pm 0.38$ & 4.59 & 0.012 & 0.06 & 0.921 & 0.016 & 0.096 \\
\hline \multicolumn{10}{|l|}{ Drug exposure (n) } \\
\hline Nicotine & 40 & 37 & & 0.01 & 0.938 & & & & \\
\hline Alcohol & 14 & 17 & & 0.37 & 0.546 & & & & \\
\hline Marijuana & 22 & 20 & & 0.17 & 0.992 & & & & \\
\hline SSRI $^{b}$ & 14 & 5 & & 3.85 & 0.050 & & & & \\
\hline Other & 15 & 6 & & 3.54 & 0.060 & & & & \\
\hline
\end{tabular}

${ }^{a}$ Rank scores for maternal education: 3, some high school; 4, graduated from high school; 5, trade school or business college; 6, some college; 7, graduated with a 4 year college degree; and 8, postgraduate work at a university.

${ }^{b}$ Antidepressant.

'Methadone, opiates, or suboxone

and voxel. The voxelwise correlation values were Fisher's Z-transformed and then compared within groups to generate connectivity maps corresponding to each group and seed region. Within-group comparisons were performed using a voxelwise one-sample $t$ test. Inclusion of a voxel in the whole-brain significant connectivity map was determined using the "combined approach" (Forman et al., 1995). Briefly, the combined approach attempts to correct for the multiple comparison problem (number of voxels) by estimating the probability of false-positive clusters in the data. More specifically, a $p$ value threshold and a cluster size threshold are "combined" to form an $\alpha$ threshold, i.e., a corrected probability of detecting a type I error. The combined approach requires an estimate of the smoothness in the data that were acquired using the preprocessed rsfRMI data from all subjects (the AFNI program 3dFWHMx). The final whole-brain combined threshold setting was as follows $(\alpha=0.05)$ : $p \leq$ 0.01 ; cluster size, 32 voxels; nearest neighbor (NN) clustering, 3 . Voxelwise multivariate modeling (the AFNI program 3dMVM) was used for quantitative comparisons between groups at the whole-brain level. $3 \mathrm{dMVM}$ is a group-analysis program that performs ANOVA- and ANCOVA-style computations (Chen et al., 2014). Explanatory variables included group, gestational age, birth weight, postnatal age (gestational age at scan), gender, and scanner. At this step, continuous variables (gestational age, birth weight, and postnatal age) were mean centered within group to control for within-group variations. Significant group main effects were detected using the same combined statistical thresholding approach outlined above, resulting in clusters with putative groupwise differences after correcting for multiple comparisons.

For each identified cluster, the mean $\mathrm{Z}$ scores were extracted, and an additional groupwise comparison was performed using ANOVA (the MATLAB function anovan) to test the effects of all potential explanatory variables. Specifically, gestational age at birth, postnatal age, birth weight, scanner, gender, maternal education, and maternal depression level were included in this full model. Here, none of the continuous variables were mean centered so that we could explicitly model the contribution of the combined within- and between-group differences of each variable to the observed variations in functional connectivity. Significant ANOVA main effects [i.e., $p \leq 0.05$ corrected for number of seeds (i.e., 4) based on false discovery rate (FDR) correction (Benjamini and Yekutieli, 2001)] were followed up with post hoc comparisons (the MATLAB function multcompare, Dunn-Sidak corrected) on the marginal mean $\mathrm{Z}$ scores to identify significant $(p \leq 0.05)$ pairwise differences. After analyses at the whole-cluster level and after observing connectivity gradient differences between PCE and NCOC, potential PCE-specific effects were further investigated at the subcluster level. Specifically, the combined thresholding approach described above was used again within the identified clusters to detect potential subclusters showing significant differences between PCE and NCOC using two-sample $t$ tests $(\alpha=0.05): p \leq 0.05$; cluster size, 11, 13, or 8 voxels for the three detected clusters, respectively (see Fig. 5); NN clustering, 3.
Finally, the specificity of the amygdala and insula seed regions was examined by using two additional seed regions that are generally unrelated to drug exposure: the left and right visual cortices. We expected no significant group differences associated with these control seeds, and, if tested to be true, our results would support the relative specific association between the two hypothesized seeds and prenatal drug exposure. Functional connectivity maps were visualized on a surface model (Caret version 5.65; Van Essen et al., 2001) created from the University of North Carolina neonate template (Shi et al., 2011). The surface model was aligned to the template space using the AFNI script @SUMA_aligntoExperiment. Connectivity differences for the drug-exposed groups were described in relation to the CTR group. Hyperconnectivity and hypoconnectivity are indicative of positive or negative shifts in connectivity relative to CTR for a given seed, respectively. However, we use the term "disrupted connectivity" to describe both types of deviations from the results of the non-exposed group.

\section{Results}

\section{Participant characteristics}

Summary statistics for gender, gestational age, postnatal age (age at scan), birth weight, maternal education, maternal depression, and categorical drug exposure were tabulated for each group (Table 1). A $\chi^{2}$ test revealed no significant difference in gender distribution $(p>0.05)$. One-way ANOVA revealed group-level differences $(p<0.05-0.001)$ for gestational age, birth weight, maternal education, and maternal depression. Effect sizes were moderate for each main effect $\left(\eta_{p}^{2}=0.10-0.14\right)$. Post hoc comparisons revealed significant group differences $(p<0.05-0.001$, Dunn-Sidak corrected) predominantly involving the PCE group. Consistent with previous reports, infants in the PCE group were born $\sim 7 \mathrm{~d}$ earlier and 14 ounces lighter than those in the NCOC and CTR groups. Similarly, mothers from the PCE group had lower education and higher depression levels. The NCOC group followed a similar trend with the PCE group for both maternal education and depression levels. Neither of the two variables differed between the PCE and NCOC groups. In subsequent analyses, these variables and the categorical factors of scanner and gender were included as potential explanatory variables in the statistical models unless noted otherwise. Non-cocaine drug use was similar between the PCE and NCOC groups ( $p \geq 0.05)$. SSRIs and other (methadone, opiates, or suboxone) drug use represented a slightly larger proportion in the PCE group (marginal significance, $p=0.05-0.06$ ). In the preprocessing pipeline, "data scrubbing" was implemented to reduce the effect of motion in the rsfMRI analyses. The number of volumes removed (Fig. 


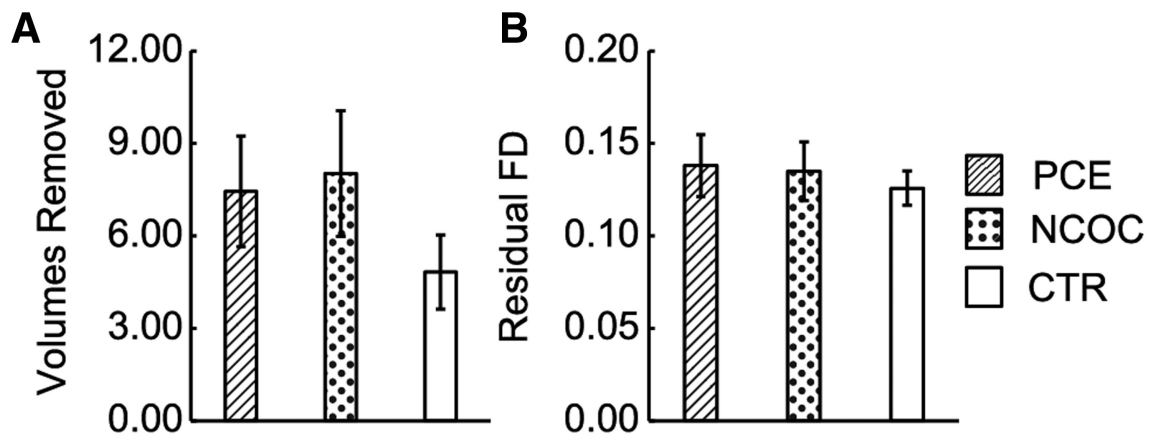

Figure 1. Comparison of motion scrubbing parameters across neonatal groups. $\boldsymbol{A}$, Number of volumes removed. $\boldsymbol{B}$, Residual framewise displacement (FD). Data are plotted as mean \pm SEM. For both motion parameters, the neonatal groups were statistically indistinguishable ( $p>0.05$, ANOVA).

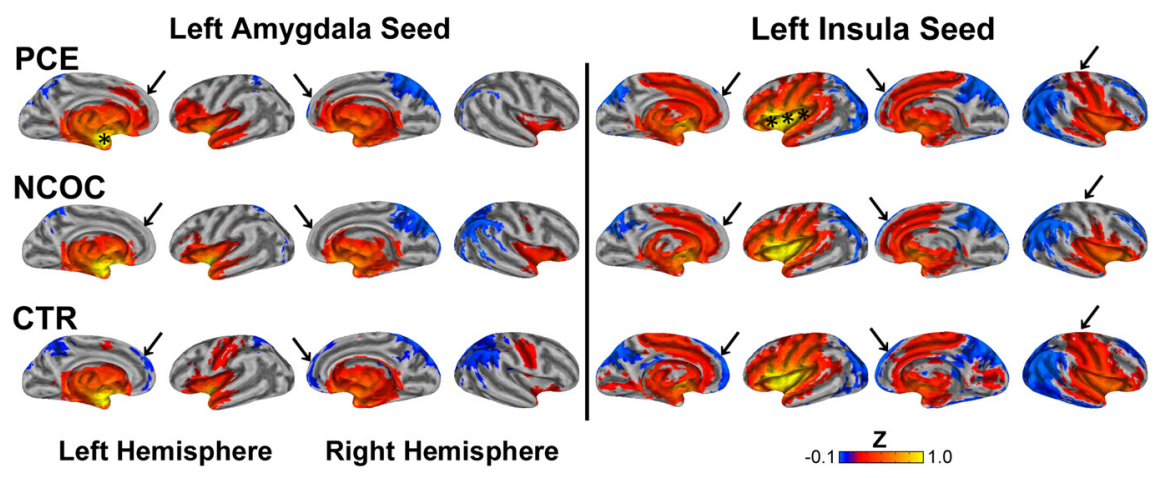

Figure 2. Visualization of functional connectivity for left amygdala and left insula seed regions across neonatal groups. Top row, PCE; middle row, NCOC; bottom row, CTR; left column, amygdala; right column, insula. Significant connectivity $(\alpha=0.05)$ is pseudocolored based on the Fisher's Z-transformed correlation measure (see color bar, bottom right) generated from the connectivity analysis. Data are visualized on the partially inflated surface model. Asterisks show the approximate locations of the seed regions. Arrows highlight regions of dissimilarity across groups.

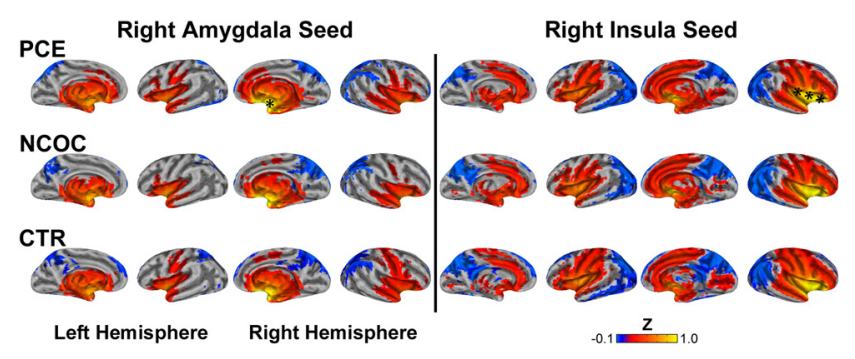

Figure 3. Visualization of functional connectivity for right amygdala and right insula seed regions across neonatal groups. Top row, PCE; middle row, NCOC; bottom row, CTR; left column, amygdala; right column, insula. Significant connectivity $(\alpha=0.05)$ is pseudocolored based on the Fisher's Z-transformed correlation measure (see color bar, bottom right) generated from the connectivity analysis. Data visualized on a partially inflated surface model. Asterisks show the approximate locations of the seed regions.

1A) and residual framewise displacement (Fig. 1B) were compared using the ANOVA. The three neonate groups were found to be statistically indistinguishable (number of volumes removed, $F_{(2,151)}=1.20, p=0.304, \eta_{p}^{2}=0.016$; and residual framewise displacement, $\left.F_{(2,151)}=0.25, p=0.782, \eta_{p}^{2}=0.003\right)$.

Amygdala and insula functional connectivity by drug-exposure group

Functional connectivity maps ( $\alpha=0.05$; see Materials and Methods) for the left amygdala (Fig. 2, left) and left insula (Fig. 2, right) seed regions were generated and pseudocolored based on the group mean Z score. Consistent with previous reports (Alcauter et al., 2013), the connectivity patterns in the CTR group (Fig. 2, CTR) are already extensive at birth. Specifically, the left amygdala seed produced widespread bilateral positive connectivity throughout the subcortex: olfactory, amygdala, pallidum, putamen, thalamus, hippocampus, parahippocampus, and caudate. The cerebellum (data not shown), vermis (data not shown), insula, temporal pole, and central gyrus (sensorimotor cortex) also displayed positive connectivity. In contrast, the superior parietal and medial-superior orbitofrontal cortices showed bilateral negative connectivity. Other regions with negative connectivity included the precuneus, cuneus, right angular gyrus-inferior parietal cortex, and superior-supplemental occipital cortices. Insular connectivity was bilaterally positive with multiple structures: subcortical (olfactory, amygdala, putamen, pallidum, hippocampus, and thalamus), insula, Heschl's gyri, operculum, temporal pole, anterior cingulate, calcarine, and sensorimotor and superior temporal cortices. Insula-generated bilateral negative connectivity is present in the occipital, frontal, and parietal cortices. Negative connectivity was also present in the cerebellum, vermis, precuneus, cuneus, rectus, angular gyrus, and posterior cingulate. Functional connectivity patterns in the NCOC and PCE groups (Fig. 2, NCOC and PCE) were generally consistent with the CTR group, but noticeable differences were also revealed (Fig. 2, arrows). Right hemisphere seeds (Fig. 3) yielded similar results, but qualitative groupwise differences were less evident.

Drug-related functional connectivity differences involving the amygdala and insula

$\mathrm{Z}$ scores for each subject and voxel in the brain were compared across the three groups using a multivariate model with the following explanatory variables: group, gestational age, birth weight, scan age, gender, and scanner. Functional connectivity group differences corresponding to the left amygdala seed yielded a significant cluster (left amygdala [frontal]) that overlapped bilaterally with the medial-inferior orbital frontal cortex, rectus, anterior cingulate, and olfactory nuclei (Fig. 4, left column). The left insula seed generated two spatially distinct clusters (Fig. 4, middle and right columns). The large anterior cluster (left insula [frontal]) overlaps bilaterally with the rectus, orbital frontal cortex, and left anterior cingulate. The superior and posterior cluster (left insula [sensorimotor]) coincides primarily with the right sensorimotor cortex. No significant grouplevel differences were detected for the right-hemisphere seeds.

The cluster associated with the left amygdala showed a pronounced connectivity gradient in the CTR group: primarily negative connectivity in the dorsal-anterior portion, with a negativeto-positive gradient, becoming positive in the ventral posterior portion of the cluster. In both the PCE and NCOC groups, this gradient is hyperconnective relative to the CTR group, and the PCE gradient is virtually entirely positive. The frontal cortex cluster associated with the left insula seed is mostly hyperconnective 
in the PCE and NCOC groups and shows little variation throughout the cluster, whereas negative connectivity predominates in the CTR group. Conversely, the left insula [sensorimotor] cluster is hypoconnective in the PCE and NCOC groups.

Clusters that showed significant group differences underwent additional post hoc statistical testing (Fig. 5). Mean Z scores were compared at the cluster level using ANOVAs. The model included all explanatory variables, including gestational age, birth weight, postnatal age, gender, scanner, maternal education, and depression level. Note that none of the variables were mean centered at this step so that we could estimate explicitly whether the combined within- and between-group differences of each variable contributed significantly to the observed variations in functional connectivity. Our results showed that all clusters produced significant ( $p \leq 0.01$, FDR corrected; Table 2) drug-group main effects. Post hoc comparisons also revealed significant ( $p<0.05-0.001$, Dunn-Sidak corrected) pairwise differences between the PCE/NCOC and CTR groups. No statistical difference between the PCE and NCOC groups were detected at this level. Prenatal drug exposure induced approximately fourfold hyperconnectivity in clusters associated with the frontal cortex. The sensorimotor cluster behaved in the opposite manner, with drug-exposed subjects showing an approximately equivalent amount of hypoconnectivity. None of the other explanatory variables included in the model produced significant main effects.

\section{Subcluster analysis and cocaine-specific effects}

Given the observed gradient differences in functional connectivity between the PCE and NCOC groups, particularly within the left amygdala [frontal] cluster as described above, we further explored potential cocainespecific effects within the three detected clusters. Consistent with the qualitative observation of the gradient difference in the left amygdala [frontal] cluster, we detected a continuous subcluster (left amygdala [frontal subcluster]) that showed significant differences $(\alpha<0.05)$ between the PCE and NCOC groups (Fig. $6 A)$. Z scores were compared by group for the detected subcluster (Fig. $6 B$ ), and statistical comparisons were again performed using the ANOVA after controlling for gestational age, birth weight, postnatal age, gender, and scanner. Overall group differences were found to be significant $\left(F_{(2,149)}=12.92, p<0.001\right)$. Post hoc comparisons between groups revealed a significant difference for PCE versus NCOC $(p=0.005)$ and PCE versus CTL $(p<0.001)$ but not for NCOC versus CTL $(p=0.344)$. No significant subclusters were detected in either of the remaining main clusters. For a subset of the PCE subjects $(n=40)$, maternal self-reported cocaine use data were available (number of times used per trimester). There was no statistical difference in connectivity for the left amygdala subcluster regarding multiple $(n=25)$

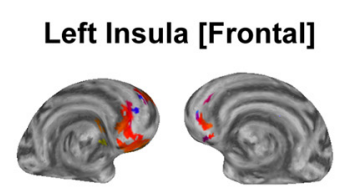

\section{Left Insula} [Sensorimotor]
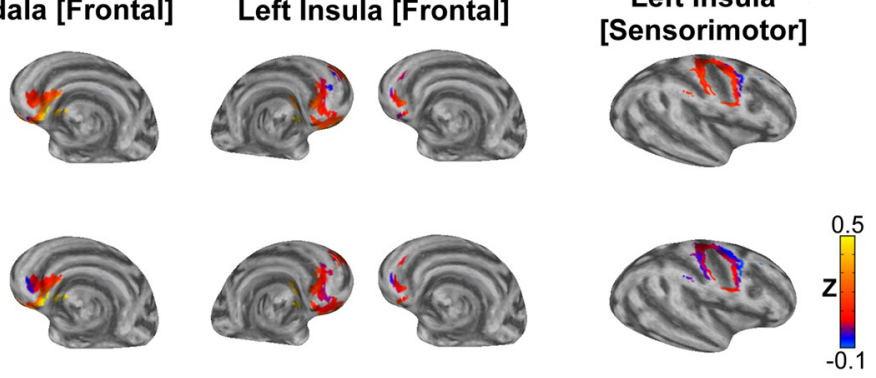

Figure 4. Visualization of groupwise differences in seed-based functional connectivity. Top row, PCE; middle row, NCOC; right, left insula [sensorimotor]. Three significant clusters ( $\alpha=0.05$, controlling for participant characteristics) are pseudocolored are visualized on the inflated surface model. Note that the surface view is slightly tilted compared with those in Figure 2 to better show the clusters. LH, Left hemisphere; RH, right hemisphere.

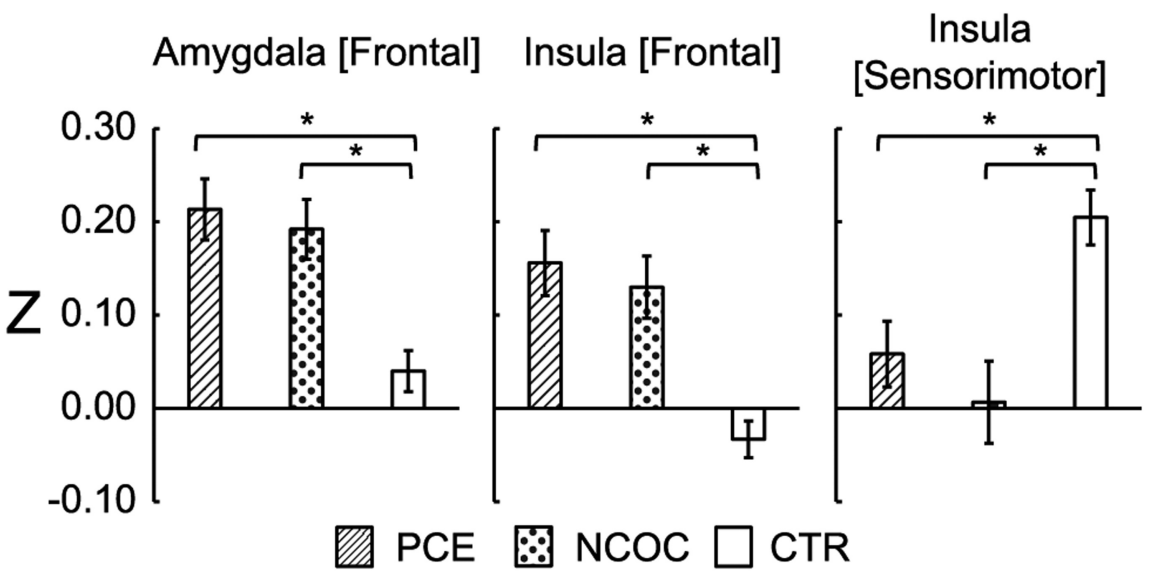

Figure 5. Post hoc comparisons of functional connectivity by group within the detected group-level significant clusters. Plots are labeled as "seed location [cluster location]." Seed regions were located in the left hemisphere. ${ }^{*} p \leq 0.05$, pairwise differences between groups (Dunn-Sidak corrected). Data are plotted for all subjects as mean \pm SEM.

Table 2. Summary of seed [cluster] post hoc analyses

\begin{tabular}{|c|c|c|c|c|c|c|c|c|c|}
\hline \multirow[b]{2}{*}{ Main effects } & \multicolumn{3}{|c|}{$\begin{array}{l}\text { Left amygdala } \\
\text { [frontal] }\end{array}$} & \multicolumn{3}{|c|}{ Left insula [frontal] } & \multicolumn{3}{|c|}{$\begin{array}{l}\text { Left insula [sensori- } \\
\text { motor] }\end{array}$} \\
\hline & $F$ & $p$ & $\eta_{p}^{2}$ & $F$ & $p$ & $\eta_{p}^{2}$ & $F$ & $p$ & $\eta_{p}^{2}$ \\
\hline Group & 6.76 & 0.002 & 0.11 & 8.13 & $<0.001$ & 0.13 & 6.54 & 0.002 & 0.11 \\
\hline Gestational age & 0.16 & 0.690 & 0.00 & 0.98 & 0.324 & 0.01 & 0.69 & 0.407 & 0.01 \\
\hline Postnatal age & 1.49 & 0.225 & 0.01 & 0.13 & 0.719 & 0.00 & 0.63 & 0.429 & 0.01 \\
\hline Weight & 1.71 & 0.193 & 0.02 & 1.55 & 0.216 & 0.01 & 0.15 & 0.699 & 0.00 \\
\hline Gender & 2.54 & 0.114 & 0.02 & 0.29 & 0.594 & 0.00 & 3.27 & 0.073 & 0.03 \\
\hline Scanner & 0.88 & 0.350 & 0.01 & 1.03 & 0.312 & 0.01 & 0.32 & 0.572 & 0.00 \\
\hline Maternal education & 0.52 & 0.473 & 0.00 & 0.01 & 0.923 & 0.00 & 0.22 & 0.641 & 0.00 \\
\hline $\begin{array}{l}\text { Maternal depression } \\
\text { Post hoc (group) }\end{array}$ & 3.15 & 0.079 & 0.03 & 2.55 & 0.113 & 0.02 & 1.11 & 0.293 & 0.01 \\
\hline PCE versus NCOC & & 0.998 & & & 0.783 & & & 0.829 & \\
\hline PCE versus CTR & & 0.013 & & & $<0.001$ & & & 0.046 & \\
\hline NCOC versus CTR & & 0.005 & & & 0.012 & & & 0.003 & \\
\hline
\end{tabular}

versus single $(n=15)$ trimester usage $\left(F_{(1,39)}=1.38, p=\right.$ $0.247)$. Likewise, there was no obvious linear relationship between connectivity and the average usage per trimester $\left(R^{2}=\right.$ $7.26 \mathrm{E}^{-06}, p=0.987$; Fig. 7 ). Finally, to rule out non-cocaine 
A

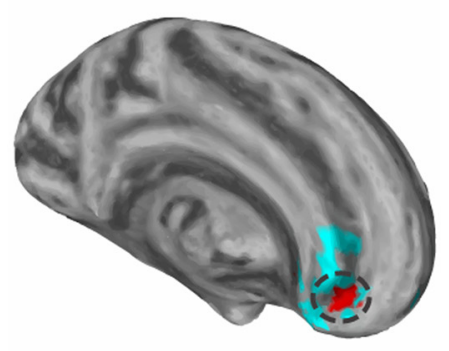

B

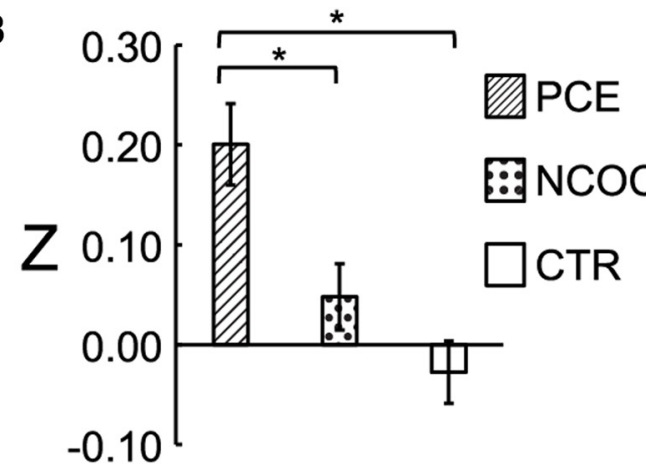

Figure 6. Cocaine-specific effect within the amygdala frontal subcluster. $\boldsymbol{A}$, Visualization of the subcluster (highlighted in red with the original cluster in blue). $\boldsymbol{B}$, Post hoc comparison of functional connectivity by group within the detected subcluster. ${ }^{*} p \leq$ 0.05, pairwise differences between groups (Dunn-Sidak corrected). Data are plotted as mean \pm SEM.

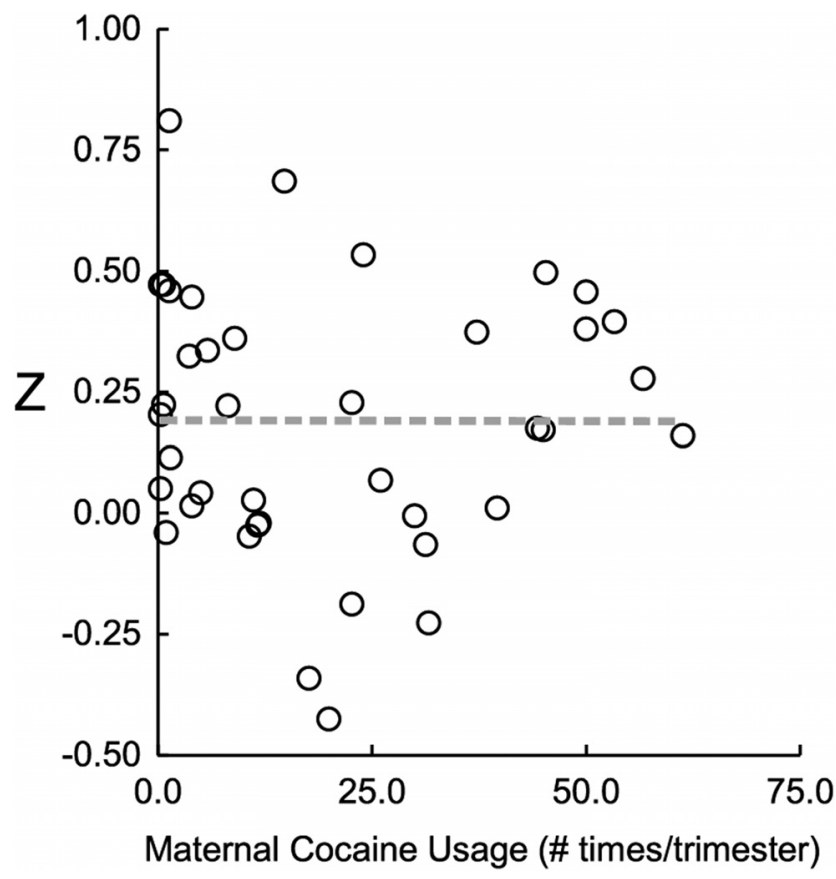

Figure 7. Relationship between functional connectivity $(Z)$ and average cocaine usage per trimester for the amygdala frontal subcluster. Data points (open circles) correspond to individual subjects. The dashed line is the best linear fit $\left(R^{2}=7.26 \mathrm{E}^{-06}, p=0.987\right)$.

Table 3. Summary of drug specificity for the detected subcluster

\begin{tabular}{llll}
\hline & \multicolumn{2}{l}{ Left amygdala [frontal subcluster] } \\
\cline { 2 - 4 } Main effects & $F$ & $P$ & $\eta_{p}^{2}$ \\
\hline Cocaine & 6.17 & 0.015 & 0.07 \\
Nicotine & 0.66 & 0.420 & 0.01 \\
Alcohol & 0.46 & 0.499 & 0.01 \\
Marijuana $_{\text {SSRls }^{a}}$ & 0.28 & 0.597 & 0.00 \\
Others $^{b}$ & 1.97 & 0.164 & 0.02 \\
\hline
\end{tabular}

${ }^{a}$ Antidepressant.

${ }^{b}$ Methadone, opiates, or suboxone.

drug use as a confounding factor and to test the specificity of cocaine for the detected subcluster, we tested the effect of drug type (cocaine, nicotine, alcohol, marijuana, antidepressant, and others) in separate ANOVAs. Cocaine was the only drug type that produced a significant effect ( $p \leq 0.05$; Table 3 ) for the PCEspecific subcluster.

\section{Specificity and GSR}

Visual cortex seeds were used to test the specificity of the reported connectivity alterations. When the left and right visual cortices were used as the seed regions, (1) no clusters showing significant grouplevel differences were detected, and (2) post hoc analyses of visual cortex connectivity within the pre-established clusters associated with the hypothesized seeds (i.e., left amygdala [frontal], left amygdala [frontal subcluster], left insula [frontal], and left insula [sensorimotor]) revealed no group main effects or pairwise differences, confirming the specificity of the previous relationships to amygdala and insula connectivity (Fig. 8). Finally, post hoc analyses were repeated without GSR, and the results remained essentially consistent with our primary results (Fig. 9).

\section{Discussion}

We examined the neural correlates of prenatal drug exposure during the neonatal period. Results revealed significant amygdala and insula functional connectivity alterations that were mostly shared between the PCE and NCOC groups, but qualitative and quantitative cocaine-specific effects were also present. To our knowledge, this study is the first to show that maternal drug use during pregnancy alters the functional organization of the brain in neonates.

Our finding of abnormal amygdala connectivity in neonates is consistent with its very early structural-functional development (Ulfig et al., 2003). Indeed, the delineated neonatal amygdala functional connectivity maps show comprehensive connections and distributed networks (Figs. 2, 3), reflecting its remarkable in utero functional growth (Ulfig et al., 2003). Given the close relationship between the amygdala and drug effects (Meyer and Quenzer, 2005), it is likely that prenatal drug exposure has already left a "footprint" on neonatal amygdala functional connectivity. Indeed, disrupted negative connectivity between the left amygdala and prefrontal regions was observed in drugexposed neonates (Fig. 4). Negative connectivity is generally interpreted as an indicator for "functional competition" (Fox et al., 2005; Kelly et al., 2008; Gao and Lin, 2012), so the observed disruption may reflect a failure in the suppression of amygdala responses from PFCs. Consistent with our findings, smaller increases in the ventral PFC activity and less suppression of amygdala activity are reported in adolescents with PCE during a working memory task (Li et al., 2009; Li et al., 2013). However, one study in cocaine-dependent adults showed decreased positive connectivity between the amygdala and medial PFC ( $\mathrm{Gu}$ et al., 2010). This difference could arise from differential mechanisms associated with prenatal drug exposure and adult drug use. Specifically, through disruptions of various neurotransmitter/ receptor signaling pathways, prenatal drug exposure may adversely affect the developing brain by affecting the delicate process of neural proliferation (Ohtani et al., 2003), migration (Crandall et al., 2007), dendrite growth (Song et al., 2002), and axonal elongation (Wu et al., 2011). In contrast, adult drug use acts on the already "hardwired" functional system. Second, the developmental-stage differences may also underlie the discrepancies, and the reported neonatal pattern is likely subject to further developmental modification. Future studies are needed to pinpoint the exact mechanisms. Behaviorally, arousal dysregulation is believed to be one of the primary 
neurodevelopmental consequences of PCE (Coles et al., 1999; Bard et al., 2000; Mayes, 2006), and inhibitory signaling in the reward circuits between the PFC and amygdala is one pathway by which this deficit is thought to occur (Mayes, 2002). Therefore, our findings of disrupted neonatal amygdala-prefrontal negative connectivity are in line with previous behavioral results, but studies directly examining functional connectivity and behavior are needed to validate this relationship.

The insula is also reported to have some of the earliest structural and functional growth during gestation (Nieuwenhuys, 2012; Alcauter et al., 2013) and is similarly implicated in drug-related brain disruptions likely because of its multifaceted involvement in sensory perception, salience detection, emotion, and the integration of exteroceptive and interoceptive information (Nieuwenhuys, 2012; Cisler et al., 2013; Noël et al., 2013; Paulus and Stewart, 2014). Cocaine dependence in adults is associated with altered functional connectivity between the insula and prefrontal networks (Cisler et al., 2013), and reduced functional connectivity has been observed between the insula and postcentral gyrus in cocaine-addicted adults (McHugh et al., 2013). Our findings of disrupted insula-frontal and insula-sensorimotor connectivity (Fig. 4) are highly consistent with these previous studies. Particularly, our observation of decreasing insula-sensorimotor connectivity parallels the report of abnormal regulation of motor responses in cocaineexposed infants (Fallone et al., 2014). Overall, our findings of adultlike disruptions of insula functional connectivity is consistent with its well documented early development and unique behavioral significance (Alcauter et al., 2014).

Mechanistically, it has long been recognized that a variety of licit and illicit drugs have strong effects on the mesocorticolimbic reward pathway, which initiates from the ventral tegmental area (VTA) and projects to the amygdala, insula, and prefrontal areas, among others (Adinoff, 2004; Meyer and Quenzer, 2005). Therefore, the common drug-related functional connectivity alterations observed in this study may be related to the shared influence of different drugs on this pathway. However, among the drugs examined, cocaine is the only stimulant that directly blocks the reuptake of dopamine (DA) and amplifies the DA signal within the reward pathway. Therefore, PCE could expose the DA-rich regions of the brain (amygdala, PFC, VTA, etc.) to higher risk of functional disruptions compared with other drugs. Indeed, we observed a prefrontal subcluster that showed more extreme disruptions in connectivity for the PCE group (Fig. 6) and was cocaine specific (Table 3), suggesting that cocaine has a greater effect on this connection over other drugs. Interestingly, this particular connectivity alteration does not appear to be dose dependent (Fig. 7), which stands in contrast to a previous behavior study showing dose-dependent relationships (Morrow et al., 2001). If independently validated, this pattern would suggest that cocaine may have a detrimental effect in the developing brain even after occasional use, thus posting additional warning for at-risk pregnant women, similar to that of prenatal alcohol exposure (Sowell et al., 2014).

Alternatively, other mechanisms could underlie the current results. For example, common environmental risks that accompany maternal drug use may be associated with the shared effects across different drugs. Among these, appetite suppression is a known side effect of cocaine, nicotine, and opiate usage. Similarly, poor prenatal care is related to illicit drug use in pregnancy (Roberts and Pies, 2011). Our observed PCE-specific effects on lower birth weight and shorter gestation may be attributable, in part, to these factors (Covert et al., 1994). However, dietcontrolled animal studies show that PCE neuronal effects are not caused by malnutrition (Ren et al., 2004). We included birth weight and gestational age as explanatory variables, and it was reassuring that neither variable produced significant effects. More importantly, our explicit analysis of maternal education and maternal depression levels showed no significant effects on functional connectivity, indicating minimal effects from these socioeconomic and maternal traits, likely because of our design of imaging of neonates that minimizes postnatal exposure to most environmental factors. Therefore, our data strongly favor drug-related mechanisms. Overall, our findings of abnormal functional connectivity in exposed neonates provide the first functional delineation of prenatal drug exposure during infancy. However, although the functional development of the brain is most dynamic during infancy, later growth/reorganization is also significant (Fair et al., 2009; Supekar et al., 2009). Furthermore, 
although we did not detect significant effects with the examined environmental variables, these factors may become increasingly more important with prolonged postnatal exposure. Therefore, it is likely that the early deficits reported here will evolve and interact with the postnatal environment, leading to either increased functional deficits (Derauf et al., 2009) or partial/full recovery.

Our results also revealed a left-lateralized pattern for functional connectivity alterations. This is consistent with previous studies showing left-lateralized amygdala connectivity abnormalities in different psychiatric disorders (Gee et al., 2012; Townsend et al., 2013). The functional bias of the left amygdala toward sustained emotional processing (Wager et al., 2003; Baas et al., 2004) and the left insula toward parasympathetic nervous system function, positive emotions, and appetitive behaviors (Craig, 2005; Harrison et al., 2010; Ibañez et al., 2010) may partly underlie the observed lateralized effects. However, future studies are again needed to rigorously examine such effects.

Several limitations deserve additional discussion. First, two scanners were used to image our subjects. However, we included scanner as a control variable, and no significant main effect was detected (Table 2). Furthermore, we performed a post hoc analysis on the interactions between scanner and group and found no significant effects ( $p>0.05$ for all four detected clusters). Second, the step of GSR does not appear to alter the main conclusion of our findings, although the likely partial volume effect associated with defining CSF and white matter regions for regression in neonatal brain may artificially reduce the differences between connectivity with and without GSR in our results (Fig. 9). Third, we have previously detected prefrontal gray matter volume reductions in PCE (Grewen et al., 2014), which could potentially mediate the observed alterations in functional connectivity. To test this possibility, we performed a correlation analysis using the overlapping subsample and found no significant relationships ( $p>0.05$ for all four detected clusters). Finally, regarding the specificity of our findings, two seed regions in the visual cortex were explored further, and no differences were detected either at the whole-brain level or within the detected clusters (Fig. 8). However, potential alterations within other reward-related pathways (e.g., thalamus and VTA) deserve additional investigation (Knutson and Greer, 2008; Cauda et al., 2011; Liu et al., 2011; Cho et al., 2013).

In conclusion, we have delineated neonatal functional connectivity alteration profiles associated with the amygdala and insula attributable to prenatal drug exposure. Connectivity abnormalities common to multiple drug exposures and cocainespecific connectivity disruptions were observed. The detection of neonatal functional connectivity abnormalities related to drug exposure greatly advances our understanding of their neural correlates. This may shed light on the early identification of specific vulnerabilities and facilitate the development of effective interventions.

\section{References}

Adinoff B (2004) Neurobiologic processes in drug reward and addiction. Harv Rev Psychiatry 12:305-320. CrossRef Medline

Afif A, Bouvier R, Buenerd A, Trouillas J, Mertens P (2007) Development of the human fetal insular cortex: study of the gyration from 13 to 28 gestational weeks. Brain Struct Funct 212:335-346. CrossRef Medline

Alcauter S, Lin W, Keith Smith J, Gilmore JH, Gao W (2013) Consistent anterior-posterior segregation of the insula during the first 2 years of life. Cereb Cortex. Advance online publication. Retrieved March 10, 2015. 10.1093/cercor/bht312. CrossRef Medline

Alcauter S, Lin W, Smith JK, Short SJ, Goldman BD, Reznick JS, Gilmore JH, Gao W (2014) Development of thalamocortical connectivity during in- fancy and its cognitive correlations. J Neurosci 34:9067-9075. CrossRef Medline

Baas D, Aleman A, Kahn RS (2004) Lateralization of amygdala activation: a systematic review of functional neuroimaging studies. Brain Res Brain Res Rev 45:96-103. CrossRef Medline

Bard KA, Coles CD, Platzman KA, Lynch ME (2000) The effects of prenatal drug exposure, term status, and caregiving on arousal and arousal modulation in 8-week-old infants. Dev Psychobiol 36:194-212. CrossRef Medline

Benjamini Y, Yekutieli D (2001) The control of the false discovery rate in multiple testing under dependency. Ann Statist 29:1165-1188. CrossRef

Biswal B, Yetkin FZ, Haughton VM, Hyde JS (1995) Functional connectivity in the motor cortex of resting human brain using echo-planar MRI. Magn Reson Med 34:537-541. CrossRef Medline

Cauda F, Cavanna AE, D'agata F, Sacco K, Duca S, Geminiani GC (2011) Functional connectivity and coactivation of the nucleus accumbens: a combined functional connectivity and structure-based meta-analysis. J Cogn Neurosci 23:2864-2877. CrossRef Medline

Chen G, Adleman NE, Saad ZS, Leibenluft E, Cox RW (2014) Applications of multivariate modeling to neuroimaging group analysis: a comprehensive alternative to univariate general linear model. Neuroimage 99:571588. CrossRef Medline

Cho YT, Fromm S, Guyer AE, Detloff A, Pine DS, Fudge JL, Ernst M (2013) Nucleus accumbens, thalamus and insula connectivity during incentive anticipation in typical adults and adolescents. Neuroimage 66:508-521. CrossRef Medline

Cisler JM, Elton A, Kennedy AP, Young J, Smitherman S, Andrew James G, Kilts CD (2013) Altered functional connectivity of the insular cortex across prefrontal networks in cocaine addiction. Psychiatry Res 213:39-46. CrossRef Medline

Coles CD, Bard KA, Platzman KA, Lynch ME (1999) Attentional response at eight weeks in prenatally drug-exposed and preterm infants. Neurotoxicol Teratol 21:527-537. CrossRef Medline

Covert RF, Schreiber MD, Tebbett IR, Torgerson LJ (1994) Hemodynamic and cerebral blood flow effects of cocaine, cocethylene and benzoylecgonine in consious and anesthetized fetal lambs. J Pharmacol Exp Ther 270:118-126. Medline

Cox RW (1996) AFNI: software for analysis and visualization of functional magnetic resonance neuroimages. Comput Biomed Res 29:162-173. CrossRef Medline

Craig ADB (2005) Forebrain emotional asymmetry: a neuroanatomical basis? Trends Cogn Sci 9:566-571. CrossRef Medline

Crandall JE, McCarthy DM, Araki KY, Sims JR, Ren JQ, Bhide PG (2007) Dopamine receptor activation modulates GABA neuron migration from the basal forebrain to the cerebral cortex. J Neurosci 27:3813-3822. CrossRef Medline

Derauf C, Kekatpure M, Neyzi N, Lester B, Kosofsky B (2009) Neuroimaging of children following prenatal drug exposure. Semin Cell Dev Biol 20:441-454. CrossRef Medline

Desikan RS, Ségonne F, Fischl B, Quinn BT, Dickerson BC, Blacker D, Buckner RL, Dale AM, Maguire RP, Hyman BT, Albert MS, Killiany RJ (2006) An automated labeling system for subdividing the human cerebral cortex on MRI scans into gyral based regions of interest. Neuroimage 31:968980. CrossRef Medline

Doria V, Beckmann CF, Arichi T, Merchant N, Groppo M, Turkheimer FE, Counsell SJ, Murgasova M, Aljabar P, Nunes RG, Larkman DJ, Rees G, Edwards AD (2010) Emergence of resting state networks in the preterm human brain. Proc Natl Acad Sci U S A 107:20015-20020. CrossRef Medline

Dow-Edwards DL, Benveniste H, Behnke M, Bandstra ES, Singer LT, Hurd YL, Stanford LR (2006) Neuroimaging of prenatal drug exposure. Neurotoxicol Teratol 28:386-402. CrossRef Medline

Eiden RD, McAuliffe S, Kachadourian L, Coles C, Colder C, Schuetze P (2009) Effects of prenatal cocaine exposure on infant reactivity and regulation. Neurotoxicol Teratol 31:60-68. CrossRef Medline

Eiden RD, Godleski S, Colder CR, Schuetze P (2014) Prenatal cocaine exposure: the role of cumulative environmental risk and maternal harshness in the development of child internalizing behavior problems in kindergarten. Neurotoxicol Teratol 44:1-10. CrossRef Medline

Fair DA, Cohen AL, Power JD, Dosenbach NU, Church JA, Miezin FM, Schlaggar BL, Petersen SE (2009) Functional brain networks develop 
from a "local to distributed" organization. PLoS Comput Biol 5:e1000381. CrossRef Medline

Fallone MD, LaGasse LL, Lester BM, Shankaran S, Bada HS, Bauer CR (2014) Reactivity and regulation of motor responses in cocaine-exposed infants. Neurotoxicol Teratol 43:25-32. CrossRef Medline

Forman SD, Cohen JD, Fitzgerald M, Eddy WF, Mintun MA, Noll DC (1995) Improved assessment of significant activation in functional magnetic resonance imaging (fMRI): use of a cluster-size threshold. Magn Reson Med 33:636-647. CrossRef Medline

Fox MD, Snyder AZ, Vincent JL, Corbetta M, Van Essen DC, Raichle ME (2005) The human brain is intrinsically organized into dynamic, anticorrelated functional networks. Proc Natl Acad Sci U S A 102:9673-9678. CrossRef Medline

Fransson P, Aden U, Blennow M, Lagercrantz H (2011) The functional architecture of the infant brain as revealed by resting-state fMRI. Cereb Cortex 21:145-154. CrossRef Medline

Gao W, Lin W (2012) Frontal parietal control network regulates the anticorrelated default and dorsal attention networks. Hum Brain Mapp 33: 192-202. CrossRef Medline

Gao W, Zhu H, Giovanello KS, Smith JK, Shen D, Gilmore JH, Lin W (2009) Evidence on the emergence of the brain's default network from 2-weekold to 2-year-old healthy pediatric subjects. Proc Natl Acad Sci U S A 106:6790-6795. CrossRef Medline

Gao W, Gilmore JH, Giovanello KS, Smith JK, Shen D, Zhu H, Lin W (2011) Temporal and spatial evolution of brain network topology during the first two years of life. PLoS One 6:e25278. CrossRef Medline

Gao W, Gilmore JH, Shen D, Smith JK, Zhu H, Lin W (2013) The synchronization within and interaction between the default and dorsal attention networks in early infancy. Cereb Cortex 23:594-603. CrossRef Medline

Gao W, Elton A, Zhu H, Alcauter S, Smith JK, Gilmore JH, Lin W (2014a) Intersubject variability of and genetic effects on the brain's functional connectivity during infancy. J Neurosci 34:11288-11296. CrossRef Medline

Gao W, Alcauter S, Elton A, Hernandez-Castillo CR, Smith JK, Ramirez J, Lin W (2014b) Functional network development during the first year: relative sequence and socioeconomic correlations. Cereb Cortex. Advance online publication. Retrieved March 10, 2015. doi:10.1093/cercor/ bhu088. CrossRef Medline

Gao W, Alcauter S, Smith JK, Gilmore JH, Lin W (2015) Development of human brain cortical network architecture during infancy. Brain Struct Funct 220:1173-1186. CrossRef Medline

Gee DG, Karlsgodt KH, van Erp TGM, Bearden CE, Lieberman MD, Belger A, Perkins DO, Olvet DM, Cornblatt BA, Constable T, Woods SW, Addington J, Cadenhead KS, McGlashan TH, Seidman LJ, Tsuang MT, Walker EF, Cannon TD (2012) Altered age-related trajectories of amygdalaprefrontal circuitry in adolescents at clinical high risk for psychosis: a preliminary study. Schizophr Res 134:1-9. CrossRef Medline

Grewen K, Burchinal M, Vachet C, Gouttard S, Gilmore JH, Lin W, Johns J, Elam M, Gerig G (2014) Prenatal cocaine effects on brain structure in early infancy. Neuroimage 101:114-123. CrossRef Medline

Gu H, Salmeron BJ, Ross TJ, Geng X, Zhan W, Stein EA, Yang Y (2010) Mesocorticolimbic circuits are impaired in chronic cocaine users as demonstrated by resting-state functional connectivity. Neuroimage 53:593601. CrossRef Medline

Harrison NA, Gray MA, Gianaros PJ, Critchley HD (2010) The embodiment of emotional feelings in the brain. J Neurosci 30:12878-12884. CrossRef Medline

Hurt H, Giannetta JM, Korczykowski M, Hoang A, Tang KZ, Betancourt L, Brodsky NL, Shera DM, Farah MJ, Detre JA (2008) Functional magnetic resonance imaging and working memory in adolescents with gestational cocaine exposure. J Pediatr 152:371-377. CrossRef Medline

Ibañez A, Gleichgerrcht E, Manes F (2010) Clinical effects of insular damage in humans. Brain Struct Funct 214:397-410. CrossRef Medline

Jenkinson M, Beckmann CF, Behrens TEJ, Woolrich MW, Smith SM (2012) Fsl. Neuroimage 62:782-790. CrossRef Medline

Kelly AM, Uddin LQ, Biswal BB, Castellanos FX, Milham MP (2008) Competition between functional brain networks mediates behavioral variability. Neuroimage 39:527-537. CrossRef Medline

Knutson B, Greer SM (2008) Anticipatory affect: neural correlates and consequences for choice. Philos Trans R Soc Lond B Biol Sci 363:3771-3786. CrossRef Medline

Lambert BL, Bauer CR (2012) Developmental and behavioral consequences of prenatal cocaine exposure: a review. J Perinatol 32:819-828. CrossRef Medline

Lester BM, Tronick EZ, LaGasse L, Seifer R, Bauer CR, Shankaran S, Bada HS, Wright LL, Smeriglio VL, Lu J, Finnegan LP, Maza PL (2002) The maternal lifestyle study: effects of substance exposure during pregnancy on neurodevelopmental outcome in 1-month-old infants. Pediatrics 110: 1182-1192. CrossRef Medline

Lester BM, Lagasse L, Seifer R, Tronick EZ, Bauer CR, Shankaran S, Bada HS, Wright LL, Smeriglio VL, Liu J, Finnegan LP, Maza PL (2003) The Maternal Lifestyle Study (MLS): effects of prenatal cocaine and/or opiate exposure on auditory brain response at one month. J Pediatr 142:279_ 285. CrossRef Medline

Li Z, Coles CD, Lynch ME, Hamann S, Peltier S, LaConte S, Hu X (2009) Prenatal cocaine exposure alters emotional arousal regulation and its effects on working memory. Neurotoxicol Teratol 31:342-348. CrossRef Medline

Li Z, Santhanam P, Coles CD, Lynch ME, Hamann S, Peltier S, Hu X (2011) Increased "default mode" activity in adolescents prenatally exposed to cocaine. Hum Brain Mapp 32:759-770. CrossRef Medline

Li Z, Santhanam P, Coles CD, Ellen Lynch M, Hamann S, Peltier S, Hu X (2013) Prenatal cocaine exposure alters functional activation in the ventral prefrontal cortex and its structural connectivity with the amygdala. Psychiatry Res 213:47-55. CrossRef Medline

Liu X, Hairston J, Schrier M, Fan J (2011) Common and distinct networks underlying reward valence and processing stages: a meta-analysis of functional neuroimaging studies. Neurosci Biobehav Rev 35:1219-1236. CrossRef Medline

Mayes LC (2002) A behavioral teratogenic model of the impact of prenatal cocaine exposure on arousal regulatory systems. Neurotoxicol Teratol 24:385-395. CrossRef Medline

Mayes LC (2006) Arousal regulation, emotional flexibility, medial amygdala function, and the impact of early experience: comments on the paper of Lewis et al. Ann NY Acad Sci 1094:178-192. CrossRef Medline

McHugh MJ, Demers CH, Braud J, Briggs R, Adinoff B, Stein EA (2013) Striatal-insula circuits in cocaine addiction: implications for impulsivity and relapse risk. Am J Drug Alcohol Abuse 39:424-432. CrossRef Medline

Meyer JS, Quenzer LF (2005) Psychopharmacology: drugs, the brain, and behavior. Sunderland, MA: Sinauer.

Morrow CE, Bandstra ES, Anthony JC, Ofir AY, Xue L, Reyes ML (2001) Influence of prenatal cocaine exposure on full-term infant neurobehavioral functioning. Neurotoxicol Teratol 23:533-544. CrossRef Medline

Nieuwenhuys R (2012) The insular cortex: a review. Prog Brain Res 195: 123-163. CrossRef Medline

Noël X, Brevers D, Bechara A (2013) A neurocognitive approach to understanding the neurobiology of addiction. Curr Opin Neurobiol 23:632638. CrossRef Medline

Ohtani N, Goto T, Waeber C, Bhide PG (2003) Dopamine modulates cell cycle in the lateral ganglionic eminence. J Neurosci 23:2840-2850. Medline

Paulus MP, Stewart JL (2014) Interoception and drug addiction. Neuropharmacology 76:342-350. CrossRef Medline

Power JD, Barnes KA, Snyder AZ, Schlaggar BL, Petersen SE (2012) Spurious but systematic correlations in functional connectivity MRI networks arise from subject motion. Neuroimage 59:2142-2154. CrossRef Medline

Rao H, Wang J, Giannetta J, Korczykowski M, Shera D, Avants BB, Gee J, Detre JA, Hurt H (2007) Altered resting cerebral blood flow in adolescents with in utero cocaine exposure revealed by perfusion functional MRI. Pediatrics 120:e1245-e1254. CrossRef Medline

Ren JQ, Malanga CJ, Tabit E, Kosofsky BE (2004) Neuropathological consequences of prenatal cocaine exposure in the mouse. Int J Dev Neurosci 22:309-320. CrossRef Medline

Roberts SC, Pies C (2011) Complex calculations: how drug use during pregnancy becomes a barrier to prenatal care. Matern Child Health J 15:333341. CrossRef Medline

Scher MS, Richardson GA, Day NL (2000) Effects of prenatal cocaine/crack and other drug exposure on electroencephalographic sleep studies at birth and one year. Pediatrics 105:39-48. CrossRef Medline

Sheinkopf SJ, Lester BM, Sanes JN, Eliassen JC, Hutchison ER, Seifer R, Lagasse LL, Durston S, Casey BJ (2009) Functional MRI and response inhibition in children exposed to cocaine in utero. Preliminary findings. Dev Neurosci 31:159-166. CrossRef Medline 
Shen D, Davatzikos C (2004) Measuring temporal morphological changes robustly in brain MR images via 4-dimensional template warping. Neuroimage 21:1508-1517. CrossRef Medline

Shi F, Yap PT, Wu G, Jia H, Gilmore JH, Lin W, Shen D (2011) Infant brain atlases from neonates to 1- and 2-year-olds. PLoS One 6:e18746-e18746. CrossRef Medline

Smith LM, Chang L, Yonekura ML, Gilbride K, Kuo J, Poland RE, Walot I, Ernst T (2001) Brain proton magnetic resonance spectroscopy and imaging in children exposed to cocaine in utero. Pediatrics 107:227-231. CrossRef Medline

Smyser CD, Inder TE, Shimony JS, Hill JE, Degnan AJ, Snyder AZ, Neil JJ (2010) Longitudinal analysis of neural network development in preterm infants. Cereb Cortex 20:2852-2862. CrossRef Medline

Song ZM, Undie AS, Koh PO, Fang YY, Zhang L, Dracheva S, Sealfon SC, Lidow MS (2002) D1 dopamine receptor regulation of microtubuleassociated protein-2 phosphorylation in developing cerebral cortical neurons. J Neurosci 22:6092-6105. Medline

Sowell ER, Charness ME, Riley EP (2014) Pregnancy: No safe level of alcohol. Nature 513:172. CrossRef Medline

Supekar K, Musen M, Menon V (2009) Development of large-scale functional brain networks in children. PLoS Biol 7:e1000157. CrossRef Medline

Thomason ME, Dassanayake MT, Shen S, Katkuri Y, Alexis M, Anderson AL,
Yeo L, Mody S, Hernandez-Andrade E, Hassan SS, Studholme C, Jeong JW, Romero R (2013) Cross-hemispheric functional connectivity in the human fetal brain. Sci Transl Med 5:173ra124. CrossRef Medline

Townsend JD, Torrisi SJ, Lieberman MD, Sugar CA, Bookheimer SY, Altshuler LL (2013) Frontal-amygdala connectivity alterations during emotion downregulation in bipolar I disorder. Biol Psychiatry 73:127135. CrossRef Medline

Ulfig N, Setzer M, Bohl J (2003) Ontogeny of the human amygdala. Ann N Y Acad Sci 985:22-33. CrossRef Medline

Van Essen DC, Drury HA, Dickson J, Harwell J, Hanlon D, Anderson CH (2001) An integrated software suite for surface-based analyses of cerebral cortex. J Am Med Inform Assoc 8:443-459. CrossRef Medline

Wager TD, Phan KL, Liberzon I, Taylor SF (2003) Valence, gender, and lateralization of functional brain anatomy in emotion: a meta-analysis of findings from neuroimaging. Neuroimage 19:513-531. CrossRef Medline

Wu CS, Jew CP, Lu HC (2011) Lasting impacts of prenatal cannabis exposure and the role of endogenous cannabinoids in the developing brain. Future Neurol 6:459-480. CrossRef Medline

Yumoto C, Jacobson SW, Jacobson JL (2008) Fetal substance exposure and cumulative environmental risk in an African American cohort. Child Dev 79:1761-1776. CrossRef Medline 